\title{
Configurações
}

Revista de sociologia

No estudar é que está o ganho?" Comparação entre ciganos com diferentes níveis de escolaridade com base em dados do Estudo Nacional sobre as

\section{Comunidades Ciganas}

"No study, no gain?" Comparison of Ciganos with different levels of education based on National Study data on Roma Communities

"Aucun gain sans étudier?» Comparaison des Ciganos selon leurs niveaux de scolarité sur la base des données de l'Étude nationale sur les communautés Ciganos

\section{Pedro Candeias}

\section{(2) OpenEdition}

\section{Journals}

\section{Edição electrónica}

URL: http://journals.openedition.org/configuracoes/3563

DOI: $10.4000 /$ configuracoes.3563

ISSN: $2182-7419$

Editora

Centro de Investigação em Ciências Sociais

\section{Edição impressa}

Paginação: 27-46

ISSN: 1646-5075

Refêrencia eletrónica

Pedro Candeias, " No estudar é que está o ganho?" Comparação entre ciganos com diferentes níveis de escolaridade com base em dados do Estudo Nacional sobre as Comunidades Ciganas »,

Configurações [Online], 18 | 2016, posto online no dia 29 dezembro 2016, consultado o 01 maio 2019

URL : http://journals.openedition.org/configuracoes/3563; DOI : 10.4000/configuracoes.3563 
Candeias, Pedro - "No estudar é que está o ganho?" Comparação entre ciganos com diferentes níveis de escolaridade com base em dados do Estudo Nacional sobre as Comunidades Ciganas. Configurações, vol. 18, 2016, pp. 27-46

\title{
No estudar é que está o ganho?" Comparação entre ciganos com diferentes níveis de escolaridade com base em dados do Estudo Nacional sobre as Comunidades Ciganas
}

\author{
PEDRO CANDEIAS* \\ Universidade do Lisboa
}

\begin{abstract}
Resumo
A dificuldade dos ciganos em aceder e permanecer no sistema de ensino é uma questão bem vincada na sociedade portuguesa. Este artigo tem como objetivo conhecer algumas caraterísticas que diferenciam ciganos portugueses que acederam e terminaram o ensino secundário ou o ensino superior face a dois outros grupos: com escolaridade até ao $3^{\circ}$ ciclo do ensino básico e iletrados. Para cumprir este fim recorre-se a dados do inquérito por questionário aplicado no âmbito do Estudo Nacional Sobre as Comunidades Ciganas. São tomados como domínios de análise as caraterísticas sociodemográficas, as relações de conjugalidade com não ciganos, a integração no mercado de trabalho, as relações com a escola e as atitudes face a desigualdades de género.
\end{abstract}

Palavras-chave: educação, ciganos portugueses, desigualdades de género, mudança social, abordagem quantitativa

\footnotetext{
Abstract

"No study, no gain?” Comparison of Ciganos with different levels of education based on National Study data on Roma Communities

The difficulty of Ciganos to access and stay in school is a recurring issue in the Portuguese society. This article aims to know some features that differentiate Portuguese Ciganos who have accessed and finished secondary education or higher education compared with two other groups: those with education up to the 3rd cycle of basic education

"Instituto de Ciências Sociais, Universidade de Lisboa; SOCIUS, Centro de Investigação em Sociologia Económica e das Organizações; ISEG-Instituto Superior de Economia e Gestão pedromecandeias@ gmail.com
} 
and the illiterate. To fulfil this purpose we used data from the questionnaire survey of the National Study of Roma Communities. The domains of analysis assumed are as follows: social and demographic characteristics, the blood relationships with non-Ciganos, integration into the labour market, the relationship with the school and the attitudes towards gender inequalities.

Keywords: education, Portuguese Ciganos gender inequalities, questionnaire surveys.

\section{Résumé}

«Aucun gain sans étudier?» Comparaison des Ciganos selon leurs niveaux de scolarité sur la base des données de l'Étude nationale sur les communautés Ciganos

Les difficultés à accéder et à rester à l'école rencontrées par les Roms est un problème évident de la société portugaise. Cet article vise à connaître certaines caractéristiques différenciant les Ciganos portugais qui ont suivi et terminé l'enseignement secondaire ou supérieur par rapport à deux autres groupes : celui qui a suivi le 3ème cycle de l'enseignement de base et celui des illettrés. Pour atteindre ce but, nous avons utilisé des données de l'enquête par questionnaire de l'Étude nationale sur les communautés Ciganos. Les domaines d'analyse sont les caractéristiques sociodémographiques, les relations de sang avec les non-Ciganos, l'intégration sur le marché du travail, la relation avec l'école et les attitudes face à des inégalités de genre.

Mots-clés : éducation, Ciganos portugais, inégalités de genre, enquêtes par questionnaire.

\section{Introdução}

Este artigo pretende comparar algumas características da população cigana portuguesa tendo como variável critério o seu nível de escolaridade. As consequências positivas de uma escolaridade mais elevada (em termos probabilísticos) são bem conhecidas: melhor rendimento, satisfação com o trabalho e com o tempo de lazer, menores probabilidades de desemprego, mais saúde, participação em associações da sociedade civil e em eleições ${ }^{1}$ (Wilkinson e Pickett 2010). A um nível macronacional, países com níveis elevados de literacia e menor abandono escolar estão também associados a menores desigualdades de rendimento (Wilkinson e Picket, 2010).

Com base nestes argumentos defende-se que a baixa escolarização dos ciganos portugueses é um dos obstáculos à redução das desigualdades sociais em Portugal. Mas não só. Tendo em conta que existe uma relação entre a escolarização e a inserção no mercado de trabalho, uma maior escolaridade por parte dos ciganos traria benefícios para as contas nacionais. O estudo 
do Banco Mundial (2010) na Bulgária, República Checa, Roménia e Sérvia demonstrou que a inclusão dos ciganos ${ }^{2}$ no mercado de trabalho implicaria ganhos na ordem dos 3,4 a 9,9 biliões de euros anuais por região. Uma vez que em Portugal a proporção de ciganos é inferior não se esperariam somas tão avultadas, mas seriam de qualquer forma mais-valias financeiras.

Para além destas consequências de nível macro, uma maior generalização da escolarização dos ciganos portugueses implica consequências positivas a nível individual, como a inserção num mercado de trabalho tradicionalmente não cigano (Magano, 2010), o que pode corresponder a uma maior diversidade nos contextos de inserção sociolaboral.

No contexto português, alguns estudos evidenciam uma maior mobilidade escolar por parte da população em estudo (p.e.: Mendes, 2012a), contudo, dizem respeito a mudanças que ocorreram a um ritmo bastante lento (Mendes e Magano, 2016). A dificuldade dos ciganos em aceder ao sistema de ensino pode ser interpretada à luz do que Bader (2005) considera um "mecanismo de práticas adscritivas". Mecanismo que resulta da apreciação (negativa) de categorias adscritivas. A categoria adscritiva étnica provem de uma categorização baseada na partilha de valores culturais fundamentais, que servem como identificadores em contextos de interação. $\mathrm{Na}$ classificação do autor, a exclusão dos ciganos dever-se-á ao que considera características adscritivas sociais e históricas, com um fechamento justificado por critérios de cultura, hábitos e estilos de vida. Pese embora as características "naturais" socialmente definidas, como o fenótipo, também possam ser relevantes.

Dado este cenário, a generalização do ensino secundário que se observou em Portugal (Figura 1) não foi acompanhado pela população cigana.

Figura 1

Percentagem da população residente com 15 anos ou mais com o ensino secundário completo ou superior

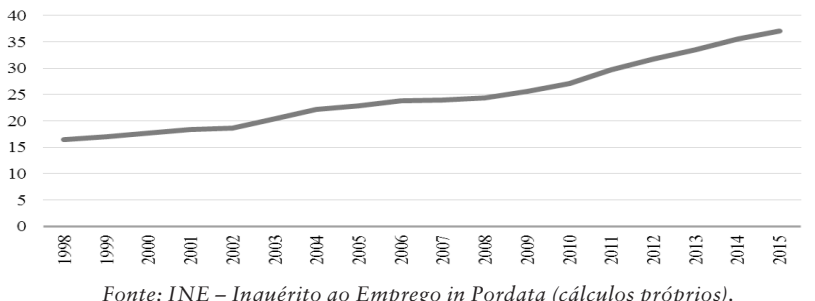

2 Embora os ciganos portugueses possuam características distintas de outros grupos europeus, existem pontos em comum nas relações que estabelecem com a escola e vice-versa. Desse modo pareceu pertinente percorrer alguma literatura internacional tomando como conceitos chave roma, sinti, gypsys ou gypsies travellers. Para facilidade de leitura todos esses termos foram traduzidos para ciganos. 
No que respeita às taxas de aprovação e reprovação, os escassos e desatualizados dados disponíveis apontam um cenário pouco favorável. Por exemplo, para o ano letivo de 1990/91 o Ministério da Educação apontava para uma taxa de reprovação dos alunos ciganos no Ensino Básico de 64,2\%, enquanto para a população total a mesma taxa seria de $34,9 \%$, com algumas oscilações mediante a região geográfica (Cortesão, 1995). Não se menospreza o efetivo crescimento que ocorreu na escolaridade dos ciganos portugueses. É especialmente relevante o aumento do regresso à escola em programas de literacia de adultos que visam compensar o abandono escolar (Mendes et al., 2014). Contudo, a igualdade não foi atingida. Esta escolarização a duas velocidades observada nos ciganos e nos não ciganos reproduz a posição desigual entre os dois grupos. É pertinente a metáfora da mobilidade intergeracional como analogia a uma escada rolante (Almeida, 1981), neste caso os ciganos estariam como a subir degraus de uma escada rolante que desce. Lógica que remete para o debate mobilidade social versus reprodução social. Para a primeira abordagem as sociedades democráticas contemporâneas são caracterizadas por um sistema de recompensas baseado no mérito individual que legitima as desigualdades sociais. Já numa lógica de reprodução social o peso da estrutura é superior ao mérito individual e as posições na estrutura de classes tendem a cristalizar-se ao longo das gerações (c.f. Silva, 2012). É nesta segunda corrente que se enquadra o fenómeno da inflação de qualificações académicas e posterior desvalorização das mesmas, identificado por Bourdieu e Passeron (1979: 81). Adaptando a esta situação, o tímido acesso de alguns ciganos ao ensino secundário e superior deverá ser entendido num contexto em que o capital escolar se torna cada vez mais massificado e por sua vez desvalorizado numa lógica economicista da lei da oferta e da procura.

No que respeita a dados empíricos recentes, o Estudo Nacional sobre as Comunidades Ciganas (doravante ENCC) em que foram inquiridos 1.599 ciganos portugueses, apurou uma parcela de 2,9\% da amostra com escolaridade de nível secundário ou superior. Valores reduzidos como estes encontram-se um pouco por toda a Europa (Liégeois, 2000 in Reimer, 2016).

Exposta a importância do aumento da escolarização dos ciganos portugueses pareceu relevante conhecer algumas características da pequena fração de ciganos mais escolarizados em comparação aos seus coétnicos menos escolarizados. Para tal recorre-se a dados recolhidos no âmbito do ENCC. Estes resultados ajudarão a lançar pistas para conhecer fatores a montante e a jusante de uma escolaridade mais elevada na população cigana portuguesa. Antes de apresentar o exercício empírico é revista alguma da literatura nacional e internacional sobre a relação dos ciganos com o sistema de ensino. 


\section{Os estudos sobre a relação entre população cigana e o sistema de ensino}

Embora a curta extensão do artigo não permita uma revisão da literatura aprofundada, pretende-se percorrer alguns dos estudos existentes de modo a conhecer as tendências gerais e as linhas de investigação da academia.

Uma parte dos estudos recenseados aborda o fenómeno a um nível macro, com o foco nas políticas implementadas. Foram relevantes as políticas de assimilação agressivas aplicadas na então União Soviética em que a escolaridade obrigatória para os ciganos teve como objetivo erradicar qualquer tipo de característica cultural deste grupo (Miskovic, 2009). Também no campo das políticas, mas num sistema democrático, o caso português foi alvo de revisão das políticas sociais implementadas após 1974, nas quais se incluem as de educação, políticas dirigidas (indiretamente ou não exclusivamente) aos ciganos em Portugal (Mendes e Magano, 2016).

A um nível meso é quase transversal o que se poderá considerar de racismo de cariz institucional. Segundo estimativas da UNICEF para a Europa central e de leste, cerca de $75 \%$ dos alunos ciganos eram colocados em turmas para alunos mentally disabled sem motivos válidos para tal (UNICEF, 2006: 24), esta prática é retratada em diversos países como na Alemanha (Reimer, 2016:3) ou a Hungria (Kende e Neményi, 2006). Outras duas formas de discriminação frequentes são as turmas e as escolas exclusivas para ciganos (ERRC, 2007).

Estudos que exploram os programas escolares enfatizam que, no geral, na Europa, a história, a música e a literatura cigana são ignoradas nos curricula escolares (Kyuchukov, 2000). Portugal não é exceção, segundo Cortesão (1995) a oferta pedagógica em Portugal é dirigida ao perfil de alunos "brancos, urbanos de classe média e católicos" (p.23). Estudos que procuraram medidas positivas mostraram que, na Áustria, alunos ciganos obtêm melhores resultados através de pedagogias mais interativas, bem como em abordagens orientadas para as comunidades (Luciak e Liegl, 2009). Também positivo foi o impacto dos "roma teacher-assistant" em turmas de alunos com 5 a 7 anos na Letónia (Zake, 2010). Embora no geral seja enfatizado o baixo desempenho escolar e a inadequação entre os conteúdos e as características dos alunos ciganos, é de salientar que, na área da matemática e especialmente do cálculo mental, estudos de etnomatemática apontam para bons resultados por parte dos alunos ciganos portugueses no ensino básico (Moreira e Pires, 2013).

A um nível micro alguns trabalhos focam as atitudes dos professores. $\mathrm{Na}$ Roménia concluiu-se que os professores não demonstravam interesse em ensinar o genocídio face aos ciganos durante a segunda guerra mundial, uma vez que contraria as atitudes negativas existentes face a esta população (Kelso, 2013). Numa etnografia em contexto escolar no norte de Itália, verificou-se que a nomeação ou reconhecimento de alunos com origem cigana como nómadas ou gypsies conferia-lhes um tratamento desigual negativo face aos não ciganos 
vis-à-vis alunos com as mesmas origens em que esta era desconhecida (Setti, 2015). Em alguns países, o bilinguismo dos alunos ciganos é ignorado pelos professores ou tomado como um handicap (Kyuchukov, 2000). Em Portugal, no estudo sobre ciganos no concelho de Bragança, os professores frisavam o fraco aproveitamento e baixa participação dos pais nas atividades em que eram solicitados (Nicolau, 2010). Também num bairro do Porto foram analisados os sentidos que os professores de uma das escolas básicas integradas atribuíam à comunidade cigana aí residente (Cortesão et al., 2005).

Outros trabalhos dedicam-se às relações interétnicas. No estudo sobre a distância social entre alunos de uma escola secundária da Croácia foi mostrada uma elevada distância social entre ciganos e outros grupos, especialmente americanos e alemães (Posavec e Hrvatic, 2000). Na Roménia, foram estudadas as opiniões que alunos ciganos e não ciganos possuíam uns face aos outros. Em termos de preferências de amizade os ciganos gostariam de ter amigos não ciganos. Já os alunos não ciganos preferiam não ter como amigos ciganos. Ambos os grupos preferiam amizades com coétnicos, embora os não ciganos com valores mais elevados (Cozma et al., 2000). Também numa lógica de relações interétnicas, em contexto espanhol, Enguita (1996) analisou a presença dos ciganos numa escola como uma situação de conflito étnico. Da parte da população não cigana foi observada hostilidade e receio que a presença destes implicasse situações de violência ${ }^{3}$; Já os ciganos recorreram a estratégicas de evitamento, quer devido ao contacto com não ciganos (considerado prejudicial especialmente para as raparigas), quer devido ao contacto com ciganos membros de grupos rivais.

Outra corrente de trabalhos centra-se nas atitudes dos pais face à escola. A população cigana na Eslováquia reconhece a importância da escola para a inserção no mercado de trabalho; contudo, considera que não é suficiente para fazer face às adversidades do quotidiano (Rusnáková et al., 2015). No Reino Unido existe uma tendência por parte dos ciganos para considerar que parte dos curricula são importantes, como a literacia e a numeracia básicas, mas o restante é tomado desnecessário para o modo de vida levado a cabo (Bhopal, 2004). Outro trabalho no Reino Unido identifica um receio por parte dos ciganos que a participação no sistema escolar leve à erosão da sua identidade cultural (Levinson e Hooley, 2014). Por outro lado, no mesmo território, tem havido por parte dos mesmos um reconhecimento da importância da educação rudimentar (literacia a numeracia), bem como a ideia de que através da escolarização as crianças poderão ter um melhor futuro (Myers et al., 2010). Num estudo

3 As representações sociais que a população não cigana possuí face aos ciganos são, em parte, resultado de um "pânico moral" veiculado pelos media, isto é, "uma ameaça aos valores e interesses de uma sociedade" (Gomes, 2013: 189). No estudo de análise de conteúdo a peças jornalísticas os ciganos (juntamente com imigrantes dos PALOP e da Europa de leste) este grupo tende a ser associado a peças referentes a crimes como "os transgressores, os vilões (e) os culpados nos acontecimentos relatados" (p.197). 
croata em que foi comparado o envolvimento dos pais na educação dos filhos, numa lógica comparativa ciganos/não ciganos, os resultados demonstraram que os primeiros possuem menor interesse em participar em trabalho voluntário, e que a satisfação com a escola e as aspirações são menores (Pahic et al., 2011). No já citado estudo sobre ciganos em Bragança os pais frisam o interesse pela escola, não obstante a existência de fortes constrangimentos (Nicolau, 2010). No também já referido estudo sobre um bairro no Porto (Cortesão et al., 2005) foram analisados os sentidos atribuídos pela comunidade cigana à escola e ao trabalho escolar. Por fim, no estudo de Silva e colaboradores (2014: cap IV) levado a cabo no norte de Portugal também foram abordadas as representações e a valorização dos ciganos face à escola, bem como a articulação entre a família e a escola. Nos discursos analisados emergiu tanto a valorização e os elogios por parte dos pais em relação à escolarização dos filhos; como a perspetivação da escola como uma obrigatoriedade no âmbito do RSI. No lado das crianças também se observou uma dualidade de posições, por um lado, atitudes negativas, resultantes de uma forte discriminação por parte dos pares não ciganos, e resultado também do desnivelamento entre a cultura dos alunos ciganos e a cultura do sistema de ensino. Por outro lado, as atitudes positivas resultaram em grande parte da valorização das escola como um meio para atingir fins, como a carta de condução.

Ainda na academia portuguesa, numa lógica mais retrospectiva, foram aprofundadas as memórias de entrevistados adultos em relação à escola (Gonçalves et al., 2006). Já Mendes (2012b) explorou as emoções de rejeição, humilhação, embaraço e vergonha que emergiam nas memórias de adultos referentes à frequência escolar.

Numa lógica longitudinal, o estudo sobre trajetórias educativas de ciganos portugueses de Mendes e Magano (2016) demonstrou que estas são tendencialmente ascendentes, sendo valorizada a escola pelos entrevistados. A posterior inserção laboral relevou-se desigual entre homens e mulheres e consoante as qualificações escolares.

Em alguns países, especialmente do leste europeu, têm vindo a ser implementadas quotas no ensino superior para alunos ciganos. Num estudo em que foram entrevistados ciganos nas universidades romenas ao abrigo de sistemas de discriminação positiva foi concluído que, embora estas quotas sejam interpretadas como uma vantagem, possuíam custos sociais acrescidos. Tal leva alguns dos alunos a ocultar a sua pertença étnica e ingressar através do contingente geral (Pantea, 2015). Também em Portugal, para o ensino básico, Magano (2010: 230) refere a ocultação da etnia cigana como uma estratégia para evitar práticas discriminatórias na escola. Com dados do Roma Education Found ${ }^{4}$ 
Garaz (2014) testou a hipótese de que a discriminação positiva no acesso ao ensino superior favorece uma pequena elite de privilegiados com características semelhantes à população não cigana. Foi concluído que, embora este grupo possua uma condição socioeconómica superior à da maioria dos ciganos, não se encontra no mesmo patamar que os não ciganos. A ideia de uma pequena elite beneficiar da escola é parcialmente corroborada em Magano (2010: 229) em que, em alguns dos casos, a escolarização é associada a uma tradição familiar. Tal como argumentado por Rusnáková e colegas “a educação é uma estratégia maioritariamente utilizada por famílias que já são educadas”(Rusnáková et al., 2015: 2725)(tradução própria).

A sucinta revisão de literatura, que de longe não cobre a extensa obra existente, permite perceber que a relação dos ciganos com a escola (e vice-versa) pode ser analisada através dos clássicos três níveis de análise: macro, meso e micro. Já no que diz respeito aos grupos estudados, os trabalhos tendem a centrar-se nos graus de ensino inferiores. O que é compreensível tendo em conta que os ciganos encontram-se mais representados nestes escalões. A exceção são os trabalhos sobre o acesso ao ensino superior, os quais, contudo, apenas focam o sistema de quotas.

\section{Método}

O material empírico no qual assenta este artigo foi recolhido no âmbito do ENCC. O projeto foi financiado pelo Alto-Comissário para as Migrações no âmbito da Estratégia Nacional para a Integração das Comunidades Ciganas (ACIDI/ GACI, 2014). O estudo teve, entre outros objetivos, produzir um retrato das comunidades ciganas portuguesas. $\mathrm{O}$ trabalho de campo referente ao inquérito por questionário decorreu entre abril e julho de 2014. Foram inquiridos 1.599 ciganos portugueses no âmbito deste estudo. Em termos geográficos cobriram-se todos os distritos de Portugal continental e 68 concelhos. Não obstante a elevada dimensão da amostra, não deve ser interpretada como um retrato estatisticamente representativo da população cigana, pois os estratos sociais superiores estão muito provavelmente subrepresentados. Demograficamente, a amostra é composta por $59 \%$ de mulheres e $41 \%$ de homens. A distribuição etária agregava $29 \%$ no escalão entre os 25 e os 34 anos, $23 \%$ tinha menos de 25 anos e 21\% tinha entre 35 e 44 anos. Uma descrição mais detalhada destes resultados pode ser encontrada na publicação em livro (Mendes et al., 2014). 


\section{Resultados}

A apresentação dos resultados inicia-se com uma descrição da variável critério. Posteriormente apresenta-se a distribuição dos fatores selecionados de acordo com os níveis de escolaridade. Os fatores são: as relações de conjugalidade com a população não cigana, a integração no mercado de trabalho, as relações com o sistema de ensino e as atitudes face a diferenças de género.

A distribuição das qualificações escolares da amostra (Quadro 1) demonstra uma população em que predomina a baixa escolarização. A situação mais frequente (27\%) é o não saber ler nem escrever (primeiro grupo). Dos que frequentaram o sistema de ensino, o mais comum é terem terminado o primeiro ciclo do ensino básico, o que representa $23 \%$ da amostra inquirida. Quase $1 / 4$ da amostra frequentou o $1^{\circ}$ ciclo do ensino básico sem o ter terminado. $\mathrm{O}$ grupo que vai desde aqueles que sabem ler e escrever até aos não chegaram a terminar o ensino secundário representa $69 \%$ dos inquiridos (segundo grupo). Apenas 3\% possui o ensino secundário completo ou um grau superior (terceiro grupo) o que corresponde a 45 indivíduos na amostra de 1.599 sujeitos.

$\mathrm{O}$ reduzido acesso ao ensino secundário e superior, pode resultar de um fechamento por motivos étnicos já referido por Bader (2005) que se articula numa relação imbricada com fatores de classe. Já no final dos anos 1970, para França, Bourdieu e Passeron (1979: 2) identificaram que filhos de trabalhadores pouco qualificados tinham possibilidades de entrar na universidade bastante inferiores quando comparados com filhos de quadros superiores ${ }^{5}$.

\section{Quadro 1}

Níveis de escolaridade e respetiva conversão nos grupos em análise

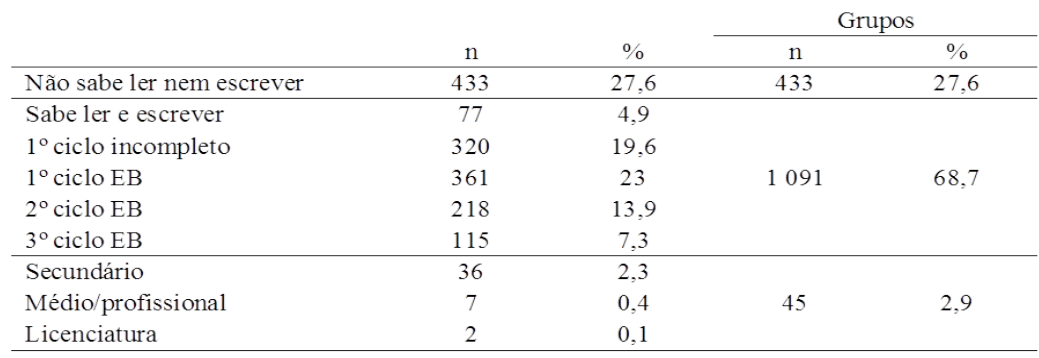

Fonte: ENCC 2014-2015 


\subsection{Sociodemográficas}

Uma primeira análise demográfica permite perceber de raiz as mais claras assimetrias que encontram-se a montante das desigualdades educacionais da amostra. A população cigana analfabeta (Figura 2) é tendencialmente envelhecida e do sexo feminino. Já o escalão que compreende a escolaridade até ao $3^{\circ}$ ciclo do ensino básico (Figura 3) apresenta-se como o mais homogéneo (embora também seja em termos quantitativos o de maior dimensão), os homens encontram-se concentrados nos escalões entre os 20 e os 39 anos, as mulheres possuem peso mais elevado no escalão entre os 20 e os 29 anos. Tal distribuição parece evidenciar um ligeiro decréscimo do analfabetismo na população cigana, que se deu de forma mais lenta para as mulheres que para os homens. O que merece uma articulação com resultados do estudo de Casa-Nova (2009) numa comunidade da periferia da cidade do Porto, em que as mulheres demonstravam um maior desejo em continuar os estudos, obstante a sua vedação a esta instituição. Esse impedimento tinha como objetivo evitar relações mistas exogâmicas que "contaminariam" o grupo. A frequência das mulheres na escola implicaria um risco acrescido de serem "faladas" (p.180).

Com a distribuição do escalão mais qualificado (ou menos desqualificado tendo em conta os níveis de escolarização da população não cigana) (Figura 4) torna-se claro que esta escolarização constitui um fenómeno extremamente recente e desigual, pois mais de metade dos inquiridos são homens com idade até aos 29 anos e o equivalente a $15 \%$ diz respeito a mulheres com idade até aos 19 anos.

Figura 2

Pirâmide etária de inquiridos que não sabem ler ou escrever

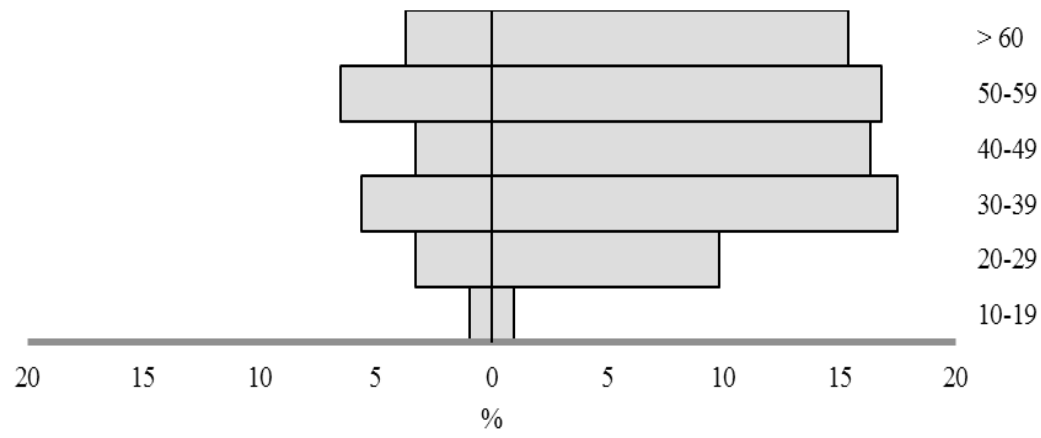


Figura 3

Pirâmide etária dos inquiridos com escolaridade até ao

$3^{\mathrm{a}}$ ciclo do ensino básico

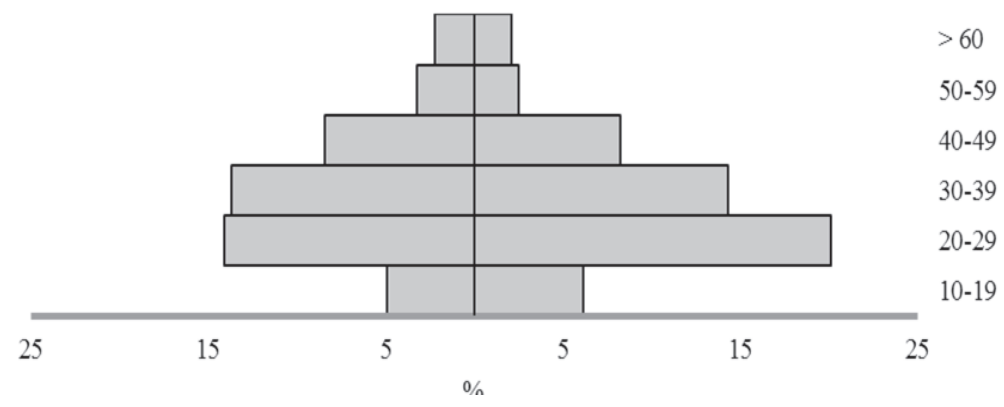

Fonte: ENCC 2014-2015

Figura 4

Pirâmide etária dos inquiridos com escolaridade de nível secundário ou superior

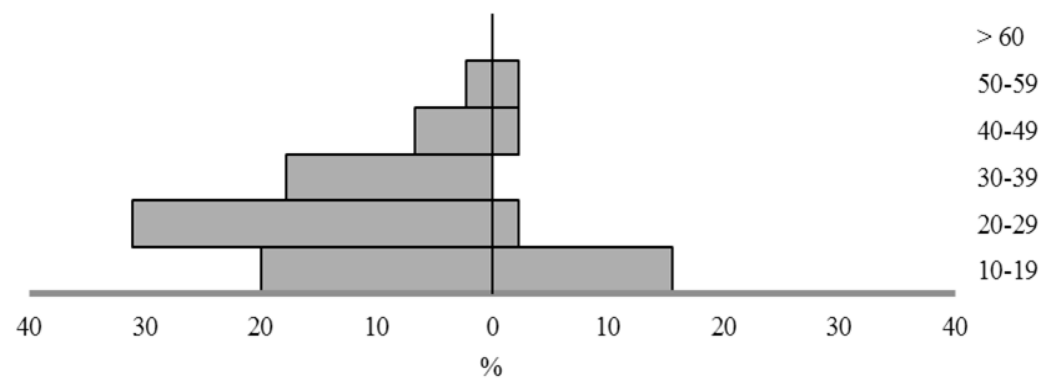

Fonte: ENCC 2014-2015

\subsection{Ascendências}

Importa perceber que fatores podem ser encontrados a montante e a jusante destes perfis educacionais. Em primeiro lugar, analisa-se a existência de ascendências (pais ou mães) mistas que podem facilitar o acesso ao sistema escolar. Estudos anteriores mostraram a importância das ascendências mistas para o prolongamento da escolaridade das mulheres (Magano, 2010: 231).

Embora estas ascendências mistas sejam residuais em qualquer dos grupos (Quadro 2), aumentam gradualmente de acordo com os três níveis de ensino. $\mathrm{O}$ que pode significar que as ascendências mistas estejam associadas a um maior contacto ou miscigenação com a população não cigana, a uma maior 
possibilidade de adotar os mesmos comportamentos e atitudes a nível escolar, bem como a menores oportunidades de presenciar discriminação negativa por parte de professores, funcionários e colegas.

\section{Quadro 2}

\section{Tipo de ascendência e cônjuge cigano ou não cigano por nível de ensino, \%}

\begin{tabular}{lccc} 
& \multicolumn{3}{c}{ Ascendências } \\
\cline { 2 - 4 } & $\begin{array}{c}\text { Não sabe ler nem } \\
\text { escrever }\end{array}$ & $\begin{array}{c}\text { Até } 3^{\circ} \text { ciclo } \\
\text { EB }\end{array}$ & $\begin{array}{c}\text { Secundário ou } \\
\text { mais }\end{array}$ \\
\hline $\begin{array}{l}\text { Pai e mãe ciganos } \\
\text { Um dos pais não é }\end{array}$ & 95,1 & 93,0 & 85,7 \\
cigano & 4,9 & 7,0 & 14,3 \\
& \multicolumn{3}{c}{ Cônjuge } \\
\hline É cigano & 95,1 & 94,2 & 88,5 \\
É não cigano & 4,9 & 5,8 & 11,5 \\
\hline
\end{tabular}

Fonte: ENCC 2014-2015

Os dados referentes à existência de cônjuges ciganos (Quadro 2) seguem no mesmo sentido que os anteriores. Os inquiridos com cônjuges não ciganos, embora sempre minoritários, são gradualmente mais frequentes de acordo com o avançar na escolaridade. Pode tratar-se de um indicador de que a escolaridade facilita o contacto com a população não cigana, como já evidenciado por Paiva (2012).

\subsection{Mercado de trabalho}

Com a análise da inserção no mercado de trabalho tendo em conta a escolaridade (Quadro 3) é notório que apenas no escalão mais escolarizado não existe uma maioria de beneficiários do RSI (Rendimento Social de Inserção) ${ }^{6}$. No grupo detentor de graduação do ensino secundário existe uma elevada proporção (29\%) de sujeitos que se encontravam a cargo da família e uma porção quase idêntica $(27 \%)$ de pessoas, cujo trabalho era a principal fonte de rendimento. É conhecido que a escolaridade surge muitas vezes associada a uma maior integração dos ciganos por via de uma atividade profissional não associada normalmente à população cigana (Magano, 2010). Se os trabalhadores mais escolarizados podem ser um sinal de maior autonomia face a benefícios sociais como o RSI, aqueles a cargo da família podem indicar que a integração escolar não se converte dire-

6 Tal não significa que a maioria dos ciganos portugueses com escolaridade até ao $3^{\circ}$ ciclo seja composta por beneficiários do RSI. Contudo, devido ao processo de amostragem não representativo, existe maior facilidade de inquirir sujeitos inativos economicamente. 
tamente em inserção na vida ativa. Pode-se ainda estar perante jovens que, após o término do ensino secundário, prosseguiram os estudos no ensino superior.

\section{Quadro 3 \\ Principal meio de vida e condição perante a atividade económica por nível de escolaridade, $\%$}

\begin{tabular}{lccc} 
& \multicolumn{3}{c}{ Principal meio de vida } \\
\cline { 2 - 4 } & $\begin{array}{c}\text { Não sabe ler nem } \\
\text { escrever }\end{array}$ & $\begin{array}{c}\text { Até } 3^{\circ} \text { ciclo } \\
\text { EB }\end{array}$ & $\begin{array}{c}\text { Secundário ou } \\
\text { mais }\end{array}$ \\
\hline Rendimento Social de & 57,9 & 62,1 & 24,4 \\
Inserção & 10,3 & 17,7 & 26,7 \\
Trabalho & 6,3 & 7,1 & 28,9 \\
A cargo da família & 16,3 & 4,3 & 0 \\
Pensão/ Reforma & 2,4 & 2,9 & 8,9 \\
Outra situação & Condição perante a atividade económica \\
\hline & 10,6 & 20,5 & 27,5 \\
\hline Ativo com profíssão & 27,3 & 36,6 & 20,0 \\
Desempregado & 7,0 & 8,2 & 10,0 \\
À procura do $1^{\circ}$ emprego & 13,7 & 3,5 & 0 \\
Reformado & 0,3 & 3,7 & 35,0 \\
Estudante & \multicolumn{3}{c}{} \\
\hline
\end{tabular}

Fonte: ENCC 2014-2015

A hipótese anterior, segundo a qual a população mais escolarizada poderá encontrar-se ainda no sistema de ensino, parece parcialmente corroborada, uma vez que 35\% dos inquiridos neste grupo era estudante (Quadro 3). Tal indica que, possivelmente, existirá em breve uma pequena nova geração de ciganos com frequência ou graduação de nível superior. Importará conhecer no futuro algumas características deste contingente. Em primeiro lugar será importante conhecer quais as suas áreas académicas, uma vez que esta é uma forma de desigualdade educacional que escapa a estatísticas menos pormenorizadas (Bourdieu e Passeron 1979: 2). Em segundo lugar, e relacionado com a questão anterior, deve ser atribuída atenção ao modo como se dá a sua inserção no mercado de trabalho. Por fim, importará conhecer as atitudes dos restantes ciganos e dos não ciganos face a esta "dupla minoria" (em termos quantitativos). Representações positivas face a este grupo poderão incentivar gerações subsequentes a prolongar os estudos. Já posições negativas poderão desincentivar os mais jovens, bem como estigmatizar os já graduados.

Continuando a análise da condição perante a atividade económica, destaca-se que no grupo mais escolarizado existe uma maior proporção de ativos com profissão. Tal leva a associar esta integração no mercado de trabalho com a frequência no sistema de ensino mais prolongada. No grupo com escolaridade até ao $3^{\circ}$ ciclo, cerca de $1 / 4$ encontrava- 
-se ativo com profissão, embora a situação mais frequente seja o desemprego $(37 \%)$. É no grupo dos iletrados que existe a maior proporção de reformados (14\%), embora o desemprego seja a situação mais frequente $(27 \%)$.

\subsection{Relações com o sistema de ensino}

Partindo da hipótese de que pessoas mais escolarizadas terão uma melhor relação com a escola, procurou-se perceber esta relação tendo como base um conjunto diverso de indicadores, nomeadamente: 1) a abstenção escolar por parte dos filhos; 2) o abandono escolar por parte de filhos e/ou netos; 3) a existência de familiares adultos que regressaram à escola; 4) as visitas à escola para tratar de assuntos referentes aos filhos ou netos (Quadro 4).

Em primeiro lugar, a inexistência total de abandono escolar a jusante apenas se observa no grupo mais escolarizado. Deve ser tido em conta que este é também um grupo de pequena dimensão e que, por se tratar do grupo mais novo, será também aquele que terá menor número de descendentes na escola. As faltas por parte dos filhos dos inquiridos são também menos frequentes no grupo mais escolarizado e aumentam gradualmente no sentido inverso aos níveis de escolaridade dos inquiridos.

Por outro lado, o regresso à escola está presente numa fatia substancial de qualquer dos grupos, o que reflete a elevada abrangência das políticas públicas dirigidas à qualificação de adultos (Gomes, 2012). Contudo, estes valores incrementam de forma gradual de acordo com a escolaridade, de $1 / 4$ dos sujeitos iletrados até $42 \%$ daqueles que chegaram no mínimo ao ensino secundário. Por fim, as visitas à escola é quase uma constante em qualquer dos grupos com poucas diferenciações entre os grupos.

\section{Quadro 4}

\section{Relações com o sistema de ensino por nível de escolaridade, \%}

\begin{tabular}{lccc} 
& $\begin{array}{c}\text { Não sabe ler nem } \\
\text { escrever }\end{array}$ & Até $3^{\circ}$ ciclo & $\begin{array}{c}\text { Secundário ou } \\
\text { mais }\end{array}$ \\
\hline $\begin{array}{l}\text { Filhos/netos abandonaram a } \\
\text { escola }\end{array}$ & 22,0 & 15,6 & 0,0 \\
$\begin{array}{l}\text { Filhos faltam a escola } \\
\text { Tem familiares que }\end{array}$ & 19,8 & 17,7 & 7,1 \\
regressaram a escola & 25,5 & 34,7 & 42,2 \\
$\begin{array}{l}\text { Vai a escola sempre que } \\
\text { pedido }\end{array}$ & 94,0 & 93,5 & 100,0 \\
\hline
\end{tabular}




\subsection{Atitudes face a diferenças de género}

De uma bateria de sete indicadores face a diferenças de género em escala de tipo Likert (Quadro 5) o único item em que são observadas diferenças graduais de acordo com os níveis de escolaridade é no que diz respeito ao sistema de ensino: "Os meninos devem andar na escola até mais tarde do que as meninas". Para perceber as diferenças entre os valores obtidos para os três grupos foram corridas uma série de Anovas. A primeira conclusão é que apenas no último item o teste de diferença de médias não apresenta valores estatisticamente significativos.

Posteriormente, os testes post hoc de Scheffe $e^{7}$ mostram que entre o primeiro e o segundo grupo as diferenças são sempre significativas; que entre o segundo e o terceiro grupo não existem diferenças significativas; e que o único item em que existem diferenças entre o primeiro e o terceiro grupo é no item "Os meninos devem andar na escola até mais tarde do que as meninas". Tal leva a pensar que o impacto da frequência do sistema de ensino nas opiniões face às diferenças de género é mais relevante entre os dois primeiros graus de ensino (o grupo iletrado é sempre mais conservador). Já o grupo mais escolarizado apenas difere do menos escolarizado em posições diretamente relacionadas com a escola, sem diferenças com o grupo que estudou no máximo até ao $3^{\circ}$ ciclo do ensino básico. A ideia de que a escolarização não implica uma mudança de atitudes face a diferenças de género já teria sido verificada com recurso a metodologias qualitativas (cf. Paiva, 2012), pese embora tenha introduzido ligeiras mudanças graduais nos comportamentos e flexibilização da lei cigana, alterações nas "maneiras de pensar" (p.310).

Duas ressalvas devem ser levantadas face a estes resultados: primeiro, a pequena subamostra do terceiro grupo pode levar a resultados menos consistentes. Segundo, a idade pode tratar-se de uma variável oculta nesta relação.

\section{Quadro5}

Atitudes face a diferenças de género por nível de escolaridade

\begin{tabular}{|c|c|c|c|}
\hline & $\begin{array}{l}\text { Não sabe ler } \\
\text { nem escrever }\end{array}$ & $\begin{array}{c}\text { Até } 3^{\circ} \\
\text { ciclo } \\
\text { EB }\end{array}$ & $\begin{array}{l}\text { Secundári } \\
\text { o ou mais }\end{array}$ \\
\hline $\begin{array}{l}\text { Os homens devem tomar as decisões familiares mais } \\
\text { importantes* }\end{array}$ & 3,81 & 3,54 & 3,84 \\
\hline $\begin{array}{l}\text { As mulheres não devem discutir com os maridos, se } \\
\text { não forem da mesma opinião*** }\end{array}$ & 3,19 & 2,81 & 2,76 \\
\hline $\begin{array}{l}\text { As mulheres de vergonha não devem frequentar } \\
\text { determinados locais sem a presença do maridos: }\end{array}$ & 4,03 & 3,84 & 3,82 \\
\hline $\begin{array}{l}\text { U ma viúva deve rapar o cabelo e usar luto } \\
\text { profundo**:* }\end{array}$ & 3,75 & 3,29 & 3,31 \\
\hline $\begin{array}{l}\text { Os meninos devem andar na escola até mais tarde do } \\
\text { que as meninas } * * *\end{array}$ & 3,59 & 3,25 & 2,84 \\
\hline $\begin{array}{l}\text { Os meninos são mais importantes do que as } \\
\text { meninas }{ }^{* * *:}\end{array}$ & 2,58 & 2,06 & 2,31 \\
\hline
\end{tabular}

Escala: $1=$ discordo totalmente, $5=$ concordo totalmente $*=p<0,05,{ }^{* *}=p<0,01,{ }^{* * *}=p<0,001$

7 Segundo Marôco (2010) o teste de Scheffe é o mais adequado quando se compara um número reduzido de grupos. 


\subsection{Análise multivariada}

Dado que é possível que parte dos resultados obtidos sejam também causados pela variável idade, o último exercício deste artigo tem como objetivo perceber o efeito que a idade possa ter nestas relações. Deste modo, foi corrida uma regressão logística, tendo como variável dependente a escolaridade de nível secundário ou superior. O modelo foi corrido em três blocos. Um primeiro testa o efeito da idade na escolaridade, o segundo bloco contempla algumas das variáveis que se mostraram relevantes anteriormente: sexo, ascendências mistas, cônjuges não ciganos, o trabalho como fonte de rendimento, o estudo como condição perante a atividade económica, a existência de familiares que regressaram à escola e as atitudes face às desigualdades de género no que respeito o acesso à escola. Um terceiro bloco agrega as variáveis de ambos os modelos anteriores (Quadro 6). O principal objetivo desta análise não é tanto o de ordenar a importância dos fatores, mas simplesmente o de perceber se o efeito da escolaridade se sobrepõe aos restantes.

O primeiro bloco, apenas com a variável idade, mostra o impacto negativo da idade nas possibilidades (odds) dos inquiridos pertencerem ao grupo mais escolarizado. O segundo modelo contempla as principais variáveis dispostas acima, excetuando a idade. Aqui é relevante o sexo masculino e a existência de familiares que tenham regressado à escola. O terceiro acrescenta a idade ao segundo modelo. As variáveis significativas no segundo modelo mantêm a sua significância, o que permite confirmar que, a idade, embora relevante, não anula a importância dos restantes fatores.

\section{Quadro 6 \\ Odds ratio e coeficientes de regressão logística para os graus de escolaridade de nível secundário ou superior}

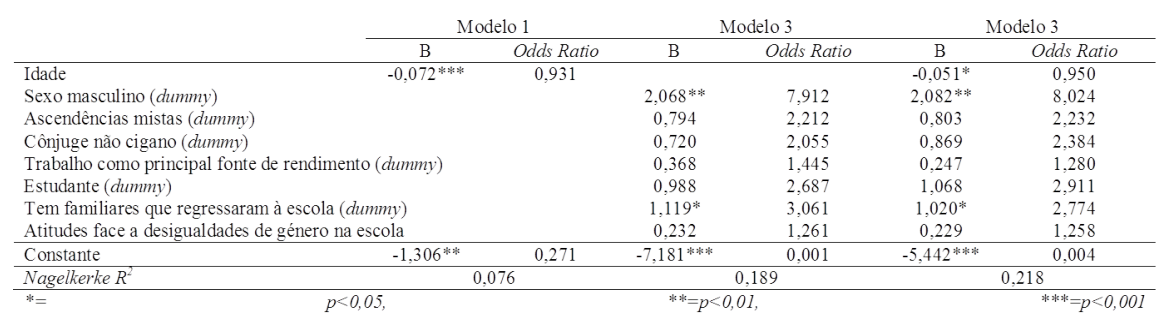




\section{Conclusão}

Foi objetivo deste artigo perceber quais as características que diferenciam os ciganos portugueses com escolaridade ao nível secundário ou superior dos restantes menos escolarizados com base em dados de um inquérito a ciganos portugueses de nível nacional.

O tema é relevante a nível macronacional no sentido em que se trata de um indicador de redução de desigualdades sociais. Se for tido em conta o pressuposto que uma maior escolarização implica uma maior integração no mercado de trabalho, esta escolarização implicará também benefícios para as contas nacionais (e.g.: maior número de contribuintes tributários e da Segurança Social, menor número de beneficiários de serviços sociais).

A um nível microindividual, o aumento da escolaridade pode refletir-se numa maior diversidade de contextos de inserção socioprofissional, bem como em processos de mobilidade social ascendente. Estudos anteriores evidenciam algumas melhorias embora ainda bastante distante de igualar com a população não cigana.

O exercício empírico permitiu perceber que, demograficamente, o grupo mais escolarizado trata-se de um pequeno grupo jovem e masculinizado. No extremo oposto, os inquiridos iletrados tendem a ser mais velhos e em grande parte mulheres.

No que diz respeito às relações de sangue ou de matrimónio com a população não cigana a grande maioria tende a ter ambos os pais ciganos e o cônjuge cigano. Mas é no grupo mais escolarizado que se observa o mais elevado número de ciganos com ascendências mistas e com cônjuges não ciganos. $\mathrm{O}$ reduzido peso destes dois fatores leva a pensar que, embora relacionado, a pertença étnica mista não será um fator determinante para a escolarização (ou determinado pela escolarização no caso dos casamentos mistos).

No que respeita a integração no mercado de trabalho o grupo mais escolarizado é aquele com a maior proporção de estudantes e de trabalhadores, o que leva a concluir que existe um impacto da escolarização na empregabilidade e na redução da dependência do RSI. Mostra também que esta escolaridade de nível secundário poderá muito bem em breve converter-se em graduação do ensino superior.

Nas relações com o sistema de ensino existe uma relação positiva entre a escolaridade e outputs positivos, com menor abandono e menor abstinência escolar por parte de filhos e netos no escalão mais escolarizado. Existe também uma tendência geral de regresso à escola, que não é um fenómeno exclusivo do grupo mais graduado.

Já as diferenças nas atitudes face a desigualdades de género tendencialmente parecem mais diferenciadas entre o grupo iletrado (mais conservador) e o grupo com escolaridade até ao final do ensino básico (mais libertário). O grupo mais escolarizado apenas se destaca estatisticamente no 
item diretamente referente à relação com a escola, o que leva a concluir que o sistema atitudinal tende a permanecer independentemente a escolaridade, embora sejam gradualmente introduzidas algumas alterações ligeiras nas suas predisposições atitudinais.

Da lista de fatores apresentados, destacam-se dois que merecem especial relevância para a compreensão deste pequeno nicho mais escolarizado: por um lado, o sexo masculino, que evidência a persistência das desigualdades de género nos ciganos portugueses. Em segundo lugar, a existência de familiares que regressaram à escola. Este fator mais otimista, pode ser consequência de imposições do RSI que uma vez postas em curso, tenderão a ser reproduzidas.

Conhecer as características deste pequeno cluster foi um primeiro passo tanto para melhor perceber quais os fatores a jusante desta escolaridade, bem como para saber algumas das suas consequências.

\section{Referências}

ACIDI/GACI (2014), Estratégia Nacional para a Integração das Comunidades Ciganas 20132020, Lisboa, ACIDI

ALMEIDA, João Ferreira de (1981), "Alguns problemas de teoria das classes sociais”, Análise Social, XVII, 66, 231-261

BADER, Veit (2005), "Etnicidade e Classe: um exercício para um mapeamento pro-teórico", Configurações, Revista de Sociologia, 1, 1, 15-38

BHOPAL, Kalwant (2004), "Gypsy Travellers and Education: Changing Needs and Changing Perceptions", British Journal of Educational Studies, 52, 1, 47-64

BOURDIEU, Pierre, e Passeron, Jean-Claude (1979), The Inheritors. French students and their relation to culture, Chicago, University of Chicago Press

CASA-NOVA, Maria José (2009), Etnografia e Produção de Conhecimento. Reflexões Críticas a Partir de Uma Investigação com Ciganos Portugueses, Lisboa, ACIDI

CORTESÃO, Luiza (1995), Reflexões crítica sobre a educação de crianças ciganas, Luiza Cortesão e Fátima Pinto (org.), O povo cigano: cidadãos na sombra: processos explícitos e ocultos de exclusão, Porto, Afrontamento, 27-36

CORTESÃO, Luiza, Stoer, Stephen, Casa-Nova, Maria José e Trindade, Rui (2005), Pontes Para Outras Viagens. Escola e Comunidade Cigana: Representações Recíprocas, Lisboa, ACIME

COZMA, Teodor, Cucos, Constantin e Momanu, Mariana (2000), "The education of Roma children in Romania: Description, difficulties, solutions”, Intercultural Education, 11, 3, 281-288

ENGUITA, Mariano F. (1996), "Escola e Etnicidade: o caso dos ciganos” Educação, Sociedade e Culturas, 6, 5-22

ERRC (2007), Stigmata: Segregated schooling of Roma in Central and Eastern Europe, a survey of patterns of segregated education of Roma in Bulgaria, the Czech Republic, Hungary, Romania, and Slovakia, Budapest, European Roma Rights Center

GARAZ, Stela (2014), "Helping the Marginalised or Supporting the Elite? Affirmative Action as a Tool for Increasing Access to Higher Education for Ethnic Roma", European Educational Research Journal, 13, 3, 295-311

GOMES, Maria do Carmo (2012), Qualificar adultos em Portugal: políticas públicas e dinâmicas sociais, Tese de Doutoramento em Sociologia, ISCTE-IUL 
GOMES, Sílvia (2013), "A construção do pânico moral sobre os ciganos e os imigrantes na imprensa diária portuguesa”, Revista Latitudes, 7, 2, 187-217

GONÇALVES, Alda, Garcia, Orlando e Barrerto, Pedro (2006), Tradição e Prospectiva nos Meandros da Economia Cigana: Circuitos Peri-Económicos na Grande Lisboa, Lisboa, ACIME

KELSO, Michelle (2013), “'And Roma were victims, too.' The Romani genocide and Holocaust education in Romania", Intercultural Education, 24,1-2, 61-78

KENDE, Anna e Neményi, Maria (2006), "Selection in education: the case of Roma children in Hungary”, Equal Opportunities International, 25, 7, 506 - 522

KYUCHUKOV, Hristo (2000), "Transformative education for Roma (Gypsy) children: An insider's view”, Intercultural Education, 11, 3, 273-280

KYUCHUKOV, Hristo (2007), "Good practices in Roma education in Bulgaria during the years of transition", Intercultural Education, 18, 1, 29-39

LEVINSON, Martin e Hooley, Neil (2014), "Supporting the learning of nomadic communities across transnational contexts: exploring parallels in the education of UK Roma Gypsies and Indigenous Australians", Research Papers in Education, 29, 4, 373-389

LUCIAK, Mikael e Liegl, Barbara (2009), "Fostering Roma students' educational inclusion: a missing part in teacher education", Intercultural Education, 20, 6, 497-509

MAGANO, Olga (2010), “Tracejar vidas normais” Estudo qualitativo sobre a integração social de indivíduos de origem cigana na sociedade portuguesa, Tese de Doutoramento em Sociologia. Especialidade em Relações Interculturais, Universidade Aberta

MARÔCO, João (2010), Análise Estatística com o PASW Statistics (ex-SPSS), Pêro Pinheiro, Report Number

MAURITTI, Rosário (2003), Caracterização e Origens Sociais, João Ferreira de Almeida, et al, Diversidade na Universidade. Um inquérito aos estudantes de licenciatura, Oeiras, Celta, 13-30

MENDES, Manuela (2012a), Identidades, Racismo e Discriminação: Ciganos da AML, Casal de Cambra, Caleidoscópio

MENDES, Manuela (2012b), "Representations About Discrimination Practices in the Education System Built by Gypsies (Ciganos) in the Lisbon Metropolitan Area (Portugal)", SAGE Open, 1-10

MENDES, Manuela e Magano, Olga (2016), "School pathways and economic practices of Portuguese Ciganos: some continuities and changes", Social Identities, 1-16

MENDES, Manuela, Magano, Olga e Candeias, Pedro (2014), Estudo Nacional Sobre as Comunidades Ciganas, Lisboa, ACM

MISKOVIC, Maja (2009), "Roma education in Europe: in support of the discourse of race", Pedagogy, Culture \& Society, 17, 2, 201-220

MOREIRA, Moreira e Pires, Gisela (2013), O processo educativo das crianças ciganas e a aprendizagem da matemática, Ana Isabel Afonso (org.), Etnografias com ciganos : diferenciação e resistência cultural, Lisboa, Colibri, 69-87

MYERS, Martin, Mcghee, Derek e Bhopal, Kalwant (2010), "At the crossroads: gypsy and traveller parents' perceptions of education, protection and social change”, Race, Ethnicity and Education, 13, 4, 533-548

NICOLAU, Lurdes (2010), Ciganos e Não-Ciganos em Trás-os-Montes: Investigação de um Impasse Inter-Étnico, Tese de Doutoramento em Ciências Sociais, Universidade de Trás-osMontes e Alto Douro

PAHIC, Tea, Vidovic, Vlasta Vizek e Miljevic-Ridicki, Renata (2011), "Involvement of Roma parents in children's education in Croatia: A comparative study", Journal of Research in International Education, 10, 3, 275-292 
PAIVA, Mirna Montenegro Val-do-Rio (2012), Aprender a Ser Cigano, Hoje: Empurrando e Puxando Fronteiras, Tese de Doutoramento em Educação. Especialidade em Educação de Adultos, Universidade de Lisboa

PANTEA, Maria-Carmen (2015), "Affirmative action in Romania's higher education: Roma students' perceived meanings and dilemmas”, British Journal of Sociology of Education, 36, 6, 896-914

PASCA, Eugenia Maria (2014), "Integration of the Roma population in and through Education. European Educational Experiences”, Procedia - Social and Behavioral Sciences, 142, 512-517

POSAVEC, Koraljka e Hrvatic, Neven (2000), "Intercultural education and Roma in Croatia", Intercultural Education, 11, 1, 1469-8439

REIMER, Julia (2016), "Education, ethnicity and gender. Educational biographies of 'Roma and Sinti' women in Germany”, European Journal of Social Work, http://dx.doi.org/10.1080/13 691457.2015.1126557

RUSNÁKOVÁ, Jurina, Rosinský, Rastislav, Šramková, Marianna, Cerešníková, Miroslava, Samko, Milan E Rochovská, Alena (2015), "Subjective perception of coping by destitute Roma communities in Slovakia and the importance of education as a strategy of pulling them out of poverty", Procedia - Social and Behavioral Sciences, 174, 2721-2726

SETTI, Federica (2015), “The implications of 'naming' on Roma and Sinti right to education and social inclusion: an ethnography of education among a Sinti family network", Intercultural Education, 26, 2, 114-130

SILVA, Manuel Carlos (2012), Trabalho, profissões e género: alguma mobilidade em contexto de reprodução social, Fernando Bessa Ribeiro, Manuel Carlos Silva e Ana Paula Marques (org.), Trabalho, Técnicas e Mundo, Vila Nova de Famalicão, Húmus, 135- 155

SILVA, Manuel Carlos, et al. (2014), Sina Social Cigana. História, Comunidades, Representações e Instituições, Lisboa, Colibri

UNICEF (2006), The State of the World's Children 2006: excluded and invisible, New York, UNICEF

WB (2010), Roma inclusion: An economic opportunity for Bulgaria, Czech Republic, Romania and Serbia. Washington, DC, World Bank

WILKINSON, Richard G. e Picket, Kate (2010), The Spirit Level: Why Greater Equality Makes Societies Stronger, New York, Berlin, London, Bloomsburry Press

ZAKE, Daiga (2010), "Qualitative Education For Roma Students: A Pedagogical Model For Sustainable Development”, Journal of Teacher Education for Sustainability, 12, 2, 27-37 